\title{
Glossophobia: The Fear of Public Speaking in ESL Students in Ghana
}

\author{
Solomon Ali Dansieh ${ }^{1}$, Edward Owusu ${ }^{2} \&$ Gordon Abudu Seidu ${ }^{1}$ \\ ${ }^{1}$ Department of General and Liberal Studies, Hilla Limann Technical University, Wa, Ghana \\ ${ }^{2}$ Department of Communication Studies, Sunyani Technical University, Sunyani, Ghana \\ Correspondence: Solomon Ali Dansieh, Department of General and Liberal Studies, Dr. Hilla Limann Technical \\ University, Wa, Ghana.
}

Received: March 14, 2021; Accepted: May 18, 2021; Published: May 21, 2021

The research is financed by the Ghana Government under the Faculty Development and Research Fund.

\begin{abstract}
Glossophobia, an individual's anxiety of public speaking, has been observed to be a common phenomenon among students. The present study explores factors associated with glossophobia among ESL students of a tertiary institution in Upper-West Ghana, the Dr. Hilla Limann Technical University, Wa and makes recommendations for improvement in their public speaking skills. The study combined both quantitative and qualitative research approaches in an opinion poll involving 46 participants from the Level 300 class of the Secretaryship and Management Studies of the Business School. Participants acknowledged the importance of public speaking, but conceded that at some point in their student lives, when they had to speak in public, glossophobia prevented them from making a good impression on the audience. Speaking English before a crowd was identified as the most dreaded experience. Low self-confidence in speaking in public; lack of constant speaking experience and lack of knowledge in public speaking; fear of making mistakes and being laughed at; inadequate preparation and timidity were also identified as challenges affecting participants' ability to speak English in public. To help students overcome that phobia, the study recommends that lecturers should adopt an interactive approach combined with the appropriate communication strategies to promote positive attitudes and create the desirable atmosphere for boosting students' confidence. Lecturers should also organise seminars on public speaking skills and encourage regular individual oral presentation in class so students can practise to develop positive attitudes towards public speaking.
\end{abstract}

Keywords: glossophobia, public speaking, confidence, oral presentation

\section{Introduction}

Public speaking is a process, an act and an art of making a speech before an audience (Chu, 2001). The main purpose of speech is to communicate one's ideas and feelings in order to get a desired response. As students soon to graduate to become secretaries and managers, ability to communicate well in English in public is not a luxury but a necessity. Brydon and Scott (2000) argue that "human communication is a need as basic to our well-being as the food we eat, water we drink and air we breathe." Citing compelling evidence from both clinical and case studies on the personal reasons for developing speaking skills, they contend further that when humans are deprived of this need, they are affected both physically and psychologically. The ability to skillfully express one's thoughts and sentiments publicly is crucial for the satisfaction of both our self- and social-esteem needs (Ibid.). One's ability to speak well publicly helps one meet personal needs and plays an important role in one's career and self-promotion processes. When students are able to speak clearly and convincingly, it helps them achieve success in their academic lives and in their future careers.

Besides the formal classroom setting, opportunities abound for students to practise and improve upon their public speaking skills, but only the courageous see and seize them. In a typical academic environment, there are many occasions on which a student may be required to express themselves publicly. This implies that absolutely every tertiary student has ever found (or will someday find) themselves in one situation or the other where they had (or have) to speak in public. As Christensen (2002) observes, they must have experienced or will experience some form of speech anxiety in the process. Some of the common identifiable occasions are: classroom presentation sessions; contributing during lectures and study group discussions; delivering formal speeches at student forums; orientation ceremonies and congregations; introducing resource persons and chairpersons at functions or delivering 
the vote of thanks at the end of such functions. Defending final project work at the end of their studies also requires students to make public oral presentations before a panel of external and internal assessors and an audience. Though these occasions provide beautiful opportunities for learners to practise and perfect their public speaking skills, many a student has oftentimes found an excuse to skip those functions for fear of being invited to talk there. Even if they attend, they end up being silent observers because of glossophobia. Each of the scenarios identified involves the assembling of a group of personalities commanding varied degrees of respect, fear and reverence from the student who is required to deliver a speech before it. Depending on the extent of formality of the occasion and the level of respect commanded by the personalities that constitute an audience, a student's anxiety in speaking at an event can be heightened considerably.

\section{The Challenge}

In spite of students' recognition of public speaking as an important and indispensable communicative skill required in both their academic and future professional lives, majority of them tend to have a great phobia for speaking before an audience of any size. This study is thus aimed at finding out from tertiary students taking the Secretarial English course what factors impede the effectiveness of their public speaking abilities.

\subsection{Objectives of the Study}

As a phenomenon that has been identified as common among tertiary students, this study sought to:

1. establish the possible causes of glossophobia among HND Secretaryhsip and Management students of Dr. Hilla Limann Technical University and

2. make recommendations for improving upon the public speaking skills of students.

\subsection{Research Questions}

To help meet the above objectives, the following questions served as a guide:

1. What are the possible causes of glossophobia among tertiary students?

2. How can students overcome the phobia and be able to speak more effectively in public?

\subsection{Significance of Study}

Possessing good oral communicative skills in English is a basic requirement of secretaries and managers. As students training to be professional secretaries and managers, identifying the causes of speech anxiety among them and knowing how to overcome them is very crucial. This study is thus considered significant because it would help draw the attention of students to the importance of public speaking skills; highlight the causes of glossophobia among them and subsequently advocate for the formulation of appropriate techniques that would help students overcome speech anxiety and improve upon their public speaking skills in general.

\subsection{An Overview of the Secretarial English VI (SMS 326E) Course}

Public speaking is an art; as such, it requires training and practice to equip students with the relevant skills and experience to speak effectively in public. This observation is affirmed by Parvis (2001:44) that, to speak effectively in front of a group is a skill that has to be taught to students and needs to be sharpened throughout college life and into the job market. The Secretarial English VI course (Code: SMS 326E) was designed with this in mind. Secretarial English VI is an English for Specific Purposes (ESP) course compulsory to all final year (Level 300) students pursuing the Higher National Diploma in Secretaryship and Management Studies in Technical Universities in Ghana. With the objective of providing students with effective oral communicative skills, a major component of the course was designed to equip students with the ability to:

- listen and speak for success;

- make oral reports and

- conduct interviews and lead conferences.

To achieve these objectives, the course covers specific topics such as:

- making speech and oral reports;

- general comments on speaking;

- controlling voice quality;

- $\quad$ knowing one's audience;

- $\quad$ speech content; 
- $\quad$ speech delivery and making an oral report.

Other oral communication-related topics that may require a student speaking before a group of people also covered by the Secretarial English VI (SMS 326E) courses include:

- $\quad$ interviewing and leading conferences;

- the job interviewer's role;

- the job interviewee's role;

- leading conferences and committee meetings

(NABPTEX, 2001)

From the summary, it is clear that even though the course content is comprehensive enough to provide students with the fundamentals in speech, the course duration of one semester tends to be inadequate for effective teaching and learning. It also fails to make sufficient provision for practical public speaking sessions.

\subsection{Related Literature}

According to Liu (2011) public speaking is the activity of speaking to a group of people. Every public speaking occasion usually will have a function: It is either intended to inform, influence or to entertain the audience. It is expected that at the end of the speech, the audience should be able to recall a message that they have learnt from the speech. In spite of the acknowledged importance of effective public speaking, Liu (2011) further observes that a lot of people, including tertiary students, have glossophobia - the fear to speak in public.

\subsection{Glossophobia: Definition of Key Terms}

Glossophobia is considered a subset of social phobia and has been defined variously as "the fear of speaking in public", "communication apprehension", "nervousness" or "speech anxiety" (McCroskey, 2001; Segar, 2018 and Black, 2019). In this study, these terms have been used interchangeably. What is a public and what is speaking or speech? The Oxford Pocket Dictionary of Current English defines "speaking" as "the activity of conveying information or expressing one's thoughts and feelings" and "public speaking" as "the activity of delivering speeches or lectures (Encyclopedia.com. 2019). Public speaking has never been an easy task as it induces apprehension or nervousness even in the most experienced public speakers. In the view of McCroskey (2001), communication apprehension broadly refers to an individual's "fear or anxiety associated with either real or anticipated communication with another person or persons." From the psychological perspective, anxiety is construed as "a state of apprehension, a vague fear that is only indirectly associated with an object" (Hilgard, Atkinson and Atkinson, 1971 cited in Scovel, 1991). Speech anxiety is thus defined as "the nervousness that a speaker feels before and/or during a presentation" (Lumen Learning, 2017). McCroskey (2001) terms the communication apprehension created by the unique combination of influences generated by audience, time and context as situational anxiety.

\subsection{The Pervasiveness of Glossophobia}

Glossophobia is one of the most common phobias with as many as $75 \%$ of people having it (Present Glossophobia.com 2001). Statistically, far more people claim that they would prefer death to giving speech. This made public speaking the greatest fear a person could have; even greater than the fear of death. According to Croston (2012) surveys about our fears commonly place fear of public speaking at the top of the list. His claim was affirmed a year later by Kaya (2013), who reports in the $30^{\text {th }}$ October, 2013 edition of The Times that in a poll that asked 2000 people to rank out of 10 how scared they were by a list of phobia, majority of participants ranked a fear of speaking as a more pressing concern than death among society's most pervasive fears. Only the thought of losing a family member was deemed a more terrifying thought. Genard (2019), on the other hand, argues that in recent times a dread of loneliness and death edge have overtaken the fear of public speaking, pushing it to the third slot. Be that as it may, the fear of public speaking still ranks significantly high on lists of social phobia.

Glossophobia is no respecter of persons and can happen anywhere - in the workplace where, at the thought of making a presentation to their superiors, a manager may experience panic attacks; at home where, before going on a job interview, a jobseeker may become emotionally troubled; at a party where the possibility of meeting someone new is curtailed by nervousness and its physical manifestations like sweaty palms (Fish, 2001). The thought of speaking in public may leave a gripped with person fear. It can also cause them to miss out on many academic, social, and career opportunities. Persons who suffer from glossophobia often shy away from any opportunity to speak. This phobia may also happen in the classroom where the student wishes that the teacher does not call on them to answer a question (Ibid.). In short, glossophobia is real and pervasive requiring that all efforts be made to curb it, especially among students the subjects of this study. The types of public speaking anxiety can be 
categorised into contexts and causes. As cankers are better fought by tackling the root causes, we dedicate the next two sub-sections to discussing what other studies have found to be the possible contexts and causes of glossophobia

\subsection{Contexts and Causes of Glossophobia among ESL Students}

Context plays a very important role in public speaking because it is the determinant of the meaning of things. Context refers to the type of setting where speech occurs. There are two anxiety contexts: pre-speech apprehension and nervousness during speech. Segar (2018) observes that some people get anxious before the speech event; while others get nervous during the speech. According to Segar, most people only experience the anxiety during, before or during the speech and not both. He argues that even the most experienced public speakers still get a little nervous before every speech. What factors are responsible for the nervousness? Various communication factors contribute to speaking anxiety or nervousness. McCroskey (2001) argues that there are four types of communication apprehension: anxiety related to trait, context, audience, and situation. According to Black (2019), a phobia may be triggered by a combination of genetic tendencies and other environmental, biological, and psychological factors (Black, 2019). The constant psychological reminder of a prior event or circumstance that led to the speaker having a fear of speaking in front of a group of people has been identified as common cause of speech anxiety among students (Strawn in Black, 2019). In Ghana, it is common among students to give nicknames, usually using words that were mispronounced or wrongly used, to persons who had a slip of tongue or stumbled over those words during speech delivery. Sometimes, the mere recall of this experience leads victims to go blank during speech, tremble or mumble over words. Kushner (2004) observes that some specific causes of glossophobia are lack of confidence, lack of constant speaking in public, natural shyness of people, laughing by people during public speaking, lack of knowledge about public speaking, inadequate preparation on public speaking, tension in public speaking, fear of making mistakes and lack of expression due to poor English speaking skills. Maintaining good eye contact is a very important technique to use during speech (Barnard, 2017), but these factors may cause a speaker to avoid making eye contact with the audience. Findings from a later research by Kankam and Boateng (2017) on the challenge of speech anxiety among some university students in Ghana affirmed lack of adequate preparation, fear of derision and apprehension following from the fear of making mistakes as some of the common causes of glossophobia. Other factors the study identified as being responsible for speech anxiety include inferiority complex and needless comparisons among students. They also observed that the main reason for some students being deficient in the use of English language was poor reading habits, overuse of vernacular and obsession with the use of pidgin.

Like his contemporaries, Genard (2019) in a recent article also identified the thought of past failures; poor or insufficient preparation; failure to do one's homework well e.g. knowing one's audience as some of the factors that can heighten anxiety levels considerably. Self-consciousness in front of large groups was also found to be one of the most commonly named reasons for performance anxiety. According to Genard (2019), the fear of appearing nervous in itself can put some speakers off even before they start to speak. Other factors that Genard identifies include the concern that others are judging us; dissatisfaction with one's abilities; discomfort with one's own body; poor breathing habits and comparing oneself with others.

Another underlying factor affecting ESL students' ability to speak confidently and fluently in English is cultural in nature. O'Neil (2006) considers "human cultural" traits to include: communicating with a verbal language of limited set of sounds and grammatical rules for constructing sentences, using age and gender to classify people, raising children and rules for distinguishing between good and bad behavior. Cherry (2012) observes that an authoritarian parenting style for instance expects a child to adhere to strict rules established by parents. Failure to abide by those rules usually results in punishment. In many cultural settings in Africa, it is almost a taboo for a child to talk when elders are talking: They must keep quiet and listen, as interrupting an elder's speech is considered a mark of rudeness and insubordination (Djane, A. 2014; Amos, 2013). This cultural practice often sows seeds of timidity in many Ghanaian youth, and if nothing is done about it, they grow up having serious communication apprehension challenges when they are expected to speak in public. Secondly, the overuse of the vernacular by many students in school contributes to their inability and anxiety to communicate well in the English language (Kankam and Boateng, 2017). It is common practice for most Ghanaian secondary and tertiary educational institutions to draw majority of their students from areas where they are located. This has negative consequences for the speaking of English language (L2) in schools in the area, as students would often prefer speaking the vernacular or local dialects to speaking the English language as a mark of identity and solidarity among their peers and sometimes with teachers they know come from those places. 


\subsection{Second or Foreign Language Anxiety}

The feeling of uneasiness, nervousness or apprehension experienced in learning or using a second or foreign language is termed as xenoglossophobia (MacIntyre and Gardner, 1994; Koshy, 2020). Xenoglossophobia, also known as Foreign Language Anxiety (FLA), has been found to be a specific anxiety that arises in classrooms and is common among Second Language learners. It often occurs if students are exposed to several negative experiences in a foreign language context (Koshy, 2020). Another research has shown that ironically the formal language classroom setting itself could constitute a highly anxiety-provoking environment for ESL students like those that participated in this study. Hashemi (2011) notes that maintaining a strict and formal classroom environment can significantly impact learners' language anxiety. The demand by such an environment for learners to be more correct and clearer by adopting or achieving native L1-like pronunciation has been identified as a huge source of anxiety for language learners. Language teachers are therefore advised to note that the more friendly and informal the language classroom environment, the less anxiety-provoking it is likely to be.

\subsection{Some Observable Symptoms of Glossophobia}

It has been observed that students with this phobia may manifest some of the following characteristics: their voices may become feeble or their bodies may tremble. Others may sweat and experience palpitations and may get anxious easily even before thinking of giving a speech or interacting with people. Some other manifestations include acute hearing, raised heartbeat and neck rigidity (Johnston, 2006).

\section{Overcoming Glossophobia among Students}

\subsection{Need to Determine the Audience}

Bailey (2012) asserts that students' public speaking skills need to be improved upon so that they can achieve greater levels of respect from colleagues and earn more promotions and life successes in general. To achieve this, a number of recommendations based on research findings have been made. Beebe and Beebe (2021), for instance, speak highly of the importance of an audience-centred approach to speech making. Audience analysis refers to the identification of the demographic variables of an audience and adapting a speech to their age, gender, ethnicity, interests, levels of understanding, educational or professional backgrounds, their attitudes, and beliefs. This approach is deemed important because it helps improve a speaker's effectiveness by creating and delivering a presentation in an appropriate manner.

\subsection{Need to Analyse the Occasion and Context}

This involves determining the purpose of the occasion: Is it for social, educational, religious or political purpose? The speaker's ability to determine the occasion along these lines is very important, as that has a direct relationship with the kind of audience to expect at the function and how formal or informal the language should be. It also helps determine if the occasion calls for a regular ritual (BJU, 1991). The speaker must check to make sure where they are coming on the programme; if there are other speakers on the programme; how much time they are expected to use and helps them become familiar with the entire programme.

Each communication event involves several dimensions but the four most commonly used ones are: physical, temporal, social-psychological, and cultural (DeVito, 2009; Cilliers, 2014). The physical dimension of communication involves "the real or touchable environment where communication occurs." A student may find themselves speaking in a classroom, a students' seminar or a large conference hall. Each of these settings can impact on the student's ability to interact with their audience. The student should be encouraged to understand that though they may have little or no control over their physical environment; they need to factor that into the planning and delivery processes of their speeches (Lumens Learning, 2017).

The temporal dimension "has to do not only with the time of the day and moment in history but also with where a particular message fits into the sequence of communication events" (DeVito, 2009). Aside the time of the day, students can face temporal dimensions related to how their speeches would be interpreted within the context of social events. Students should also be encouraged to consider how their message could fit into what happens immediately before it and also bear in mind the need to be sensitive to previous topics and be ready to subtly retailor that into their message if the need arises.

According to DeVito (2009), the social-psychological dimension of context refers to "status relationships among participants, roles and games that people play, norms of the society or group, and the friendliness, familiarity or gravity of the situation." Students should take into account the types of people in their audience and their possible reactions to a wide range of messages. Each of DeVito's four contextual dimensions can affect the context of a student's speech. Training students on how they might address the challenges posed by each would go a long way 
to helping them overcome communication apprehension and enable them get their message across more effectively to the audience.

\subsection{The Gap}

As popular as the topic of glossophobia is in communication, it is not surprising that many researches have been conducted on the fear of public speaking; however, as far as the causes of public speaking anxiety relating specifically to secretarial students in a tertiary institution in an ESL setting like Upper West Ghana's are concerned, little research has been done. As is evident from the foregoing literature review, a large body of works from psychological and communication discourses support the prevalence and debilitating impact of glossophobia in the lives of students (Bress, 2006). The subject of identifying the causes of glossophobia and finding ways of overcoming them is of great importance to the achievement of success in higher education because effective public speaking skills in the form of verbal communication is a stated learning outcome of many Ghanaian tertiary institutions, hence this study.

\section{Methodology}

This study combined qualitative and quantitative research approaches and utilized an opinion poll among final year secretarial students of the Dr. Hilla Limann Technical University (formerly Wa Polytechnic). It sought to answer the question: "What are the causes of speech anxiety among tertiary students?" Samples were acquired deliberately: The target population consisted of Level 300 Higher National Diploma (HND) Secretaryship and Management students of the Business School of Dr. Hilla Limann Technical University. The entire class of the 2018 year group participated. The respondents were selected because, having taken the Oral Presentation course as part of the Secretarial English VI (SMS326E) course and made oral presentations in class, they were considered the most suitable group most likely to have a fair knowledge about the causes of tertiary students' public speaking anxieties which this study sought to investigate. The total population of students offering the Secretaryship and Management Studies in the University (from Levels 100 - 300) was 123, but for the purpose of this present study, a total of 46 respondents, constituting the number on roll of the Level 300 class of HND Secretaryship and Management Studies were selected. As an exploratory research, the researchers used the technique of gathering information by questionnaires, where participants filled in their responses on the hard copies administered to them by the researchers. Data obtained were subsequently coded, analysed and conclusions drawn from the findings. The discussions are descriptive in nature.

\section{Findings}

The study confirmed earlier research conclusions that glossophobia is real and pervasive. It affirmed the argument that speech anxiety is experienced by persons irrespective of their gender, age or social status. The findings are presented in two parts: One part uses tables, pie charts and graphs to present the quantitative data obtained. It summarises the demographics of participants; their experiences when confronted with public speaking; what they consider as the possible causes of anxiety; their individual prior public speaking involvements; their affirmation of nervous feelings when speaking in public and what they consider as root causes of public speaking anxiety. The other part presents a qualitative analysis of responses obtained from participants through open-ended questions included in the questionnaire. The findings are discussed in turns.

Table 1. Sex Distribution of Respondents

\begin{tabular}{rlrrrr}
\hline \multirow{4}{*}{ Valid } & & Frequency & Percent & Valid Percent & Cumulative Percent \\
\cline { 3 - 6 } & Male & 10 & 21.7 & 21.7 & 21.7 \\
& Female & 36 & 78.3 & 78.3 & 100.0 \\
& Total & 46 & 100.0 & 100.0 & \\
\hline
\end{tabular}

Source: Field Data (2017)

Table 1 gives the number on roll of the Level 300 class of Secretaryship and Management Studies who participated in this study. Out of a total population of 46 , female students numbered 36 , constituting the majority of $78.3 \%$; a clear indication that the programme is a female-dominated one. Only 10 males, representing $21.3 \%$, offer the programme. 


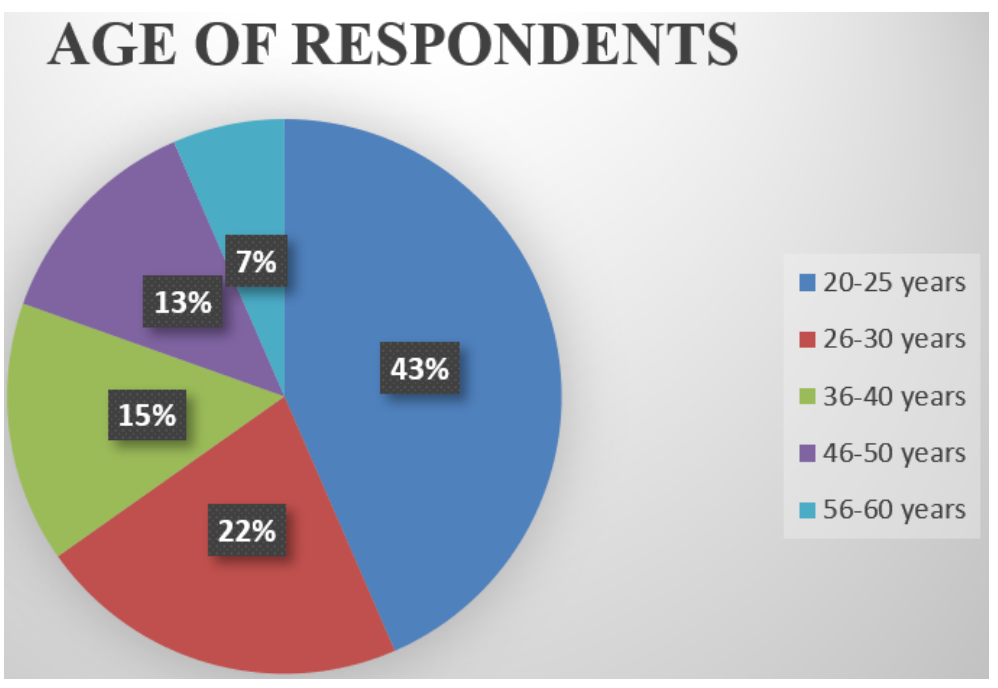

Figure 1. Age of Respondents

As far as the ages of participants are concerned, the study found that 20 of the participants, constituting the majority of $43.5 \%$, were aged between 20 and 25 years. This means that the class is quite youthful. Ten, constituting $21.7 \%$ of the participants were aged between 26 and 30 years, while those who fell within the 36-40; 46-50; 56-60 year brackets constituted $15.2 \%, 13 \%$ and $6.5 \%$ respectively. The rather high age brackets are recorded because most of the candidates who apply for Higher National Diploma usually come in as mature rather than direct applicants. Mature applicants, according to the admission requirements must have attained 25 years and must show proof of work experience. A good number of them go through all the stages in certificate courses in Secretaryship like Typist Grade 1and 2, Stenographer etc. before they apply for the HND.

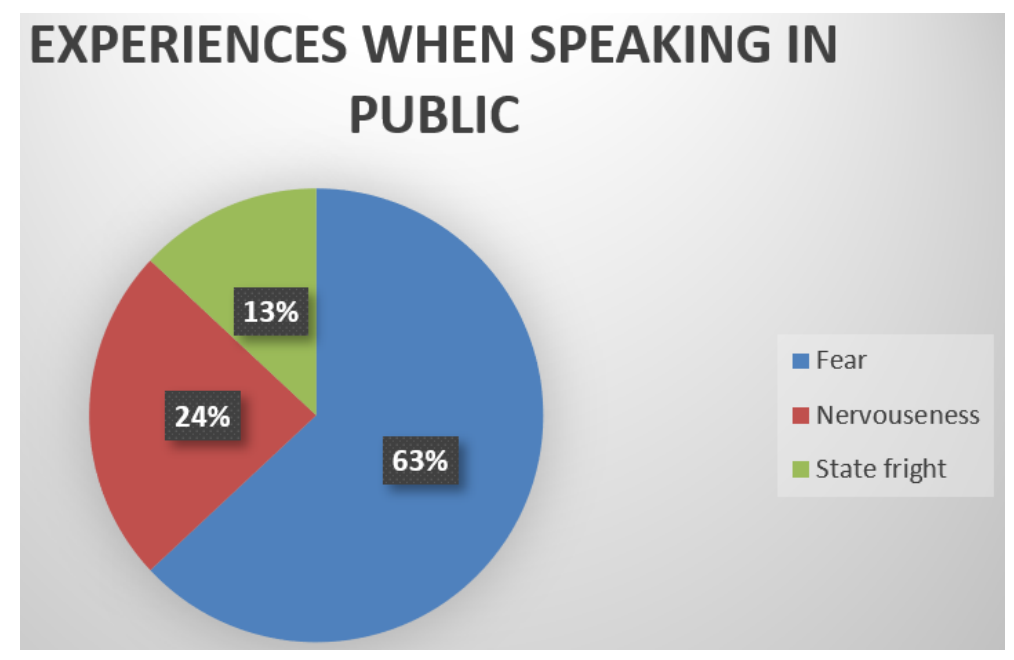

Figure 2. Students' Experience when Speaking in Public

The study also enquired from participants what experiences they have had in speaking. Majority (63\%) identified fear as the commonest experience. This goes to affirm findings by earlier researchers like Croston (2012) and Kaya (2013) that speaking in public is dreaded by many; some dreading it even more than death. A good number (23.9\%) of the student participants also recognized nervousness as a major concern when they are confronted with the task of speaking before a crowd. Stage fright was identified by $13 \%$ of respondents as another unpleasant experience they grapple with when it comes to speaking before the public. 


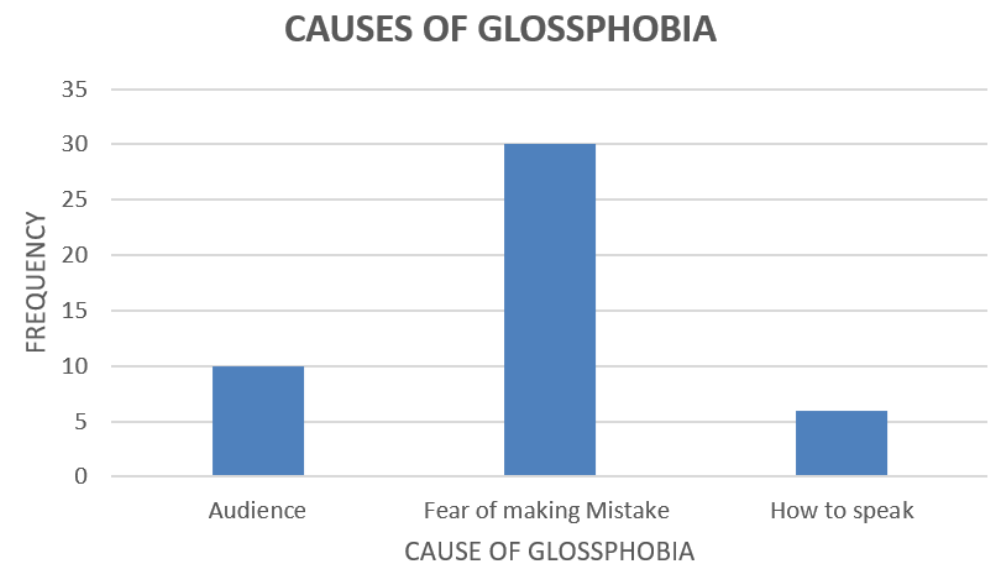

Figure 3. Possible Causes of Glossophobia among Students

As far as the causes of speech anxiety are concerned, majority (65.2\%) of respondents identified the fear of making mistakes as the main anxiety-causing factor in public speaking. Given that the study was conducted in an ESL setting, this finding is significant. The respondents did not indicate that they experience anxiety when speaking generally, or even in their mother tongue. Once their fear relates to the speaking of English language in public, we argue that our subjects experienced xenoglossophobia - the unease, nervousness or apprehension experienced in learning or using a second or foreign language (MacIntyre and Gardner, 1994). The second group of respondents representing $21.7 \%$ rather considered audience as their major challenge in public speech making. The remaining $(13 \%)$ identified lack of knowledge in public speaking as their main challenge.

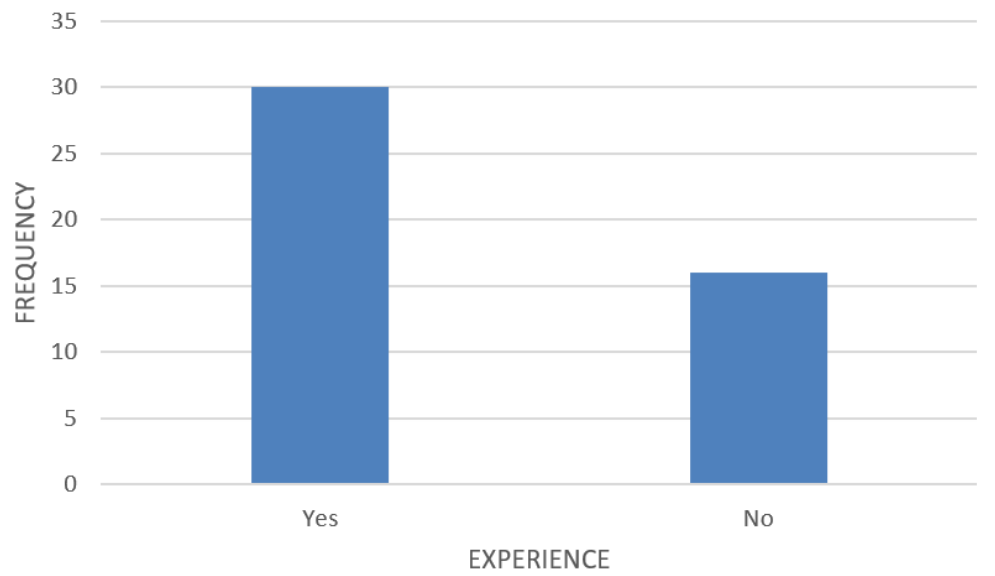

Figure 4. Students' Prior Experience in Public Speaking

The next question sought to find out from students whether they have ever had any experience in speaking in public. To this, majority (65.2\%) responded in the affirmative, while $34.8 \%$ said they had never done that. From a class where majority of the students attests to having spoken in public before, one would expect that their public speaking nervousness would be minimal, but as Table 2 below illustrates, it is rather the opposite.

Table 2. Impact of public speaking on students

\begin{tabular}{rrrrrr}
\hline \multicolumn{5}{c}{ Does public speaking cause nervousness in you? } \\
\hline Valid & Yes & Frequency & Percent & Valid Percent & Cumulative Percent \\
Total & & 46 & 100.0 & 100.0 & 100.0 \\
\hline
\end{tabular}

Source: Field Data (2017) 
All 46 participants in the study acknowledged that public speaking causes nervousness in them. Their assertion corroborates findings of earlier studies (Fish, 2009; Black, 2019; McCroskey, 2001; Kushner, 2004) on the pervasiveness of the fear of speaking in public.

\section{ROOT CAUSES OF FEAR OF PUBLIC SPEAKING AMONG STUDENTS}

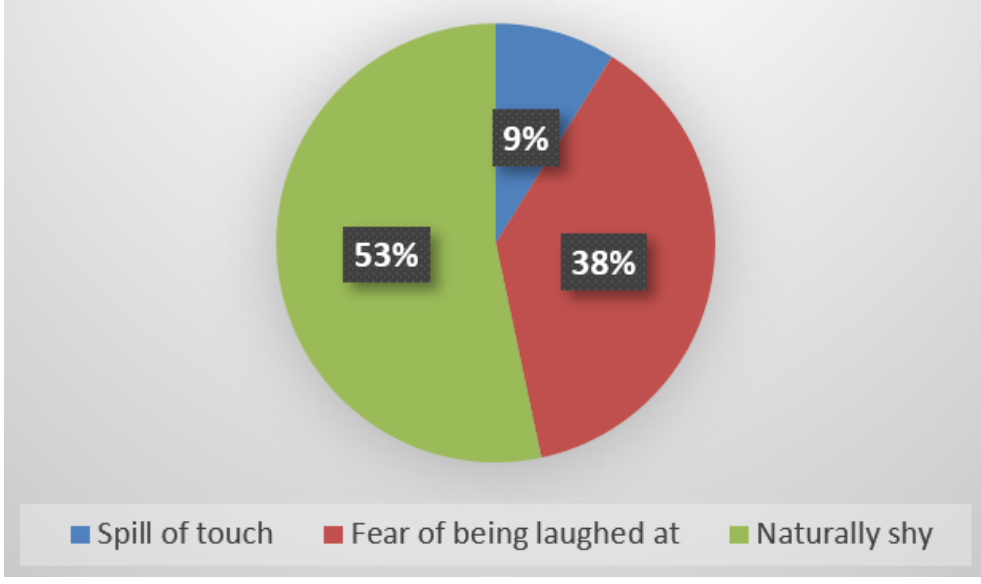

Figure 5. Students’ Perspectives on Root Causes of Glossophobia

Majority (53\%) of the respondents identified natural shyness as the root cause of the fear in public speaking, a confirmation of a view that Kushner (2004) has earlier expressed. This was followed by the fear of being laughed at and spill of touch with $37 \%$ and $10 \%$ respectively.

\subsection{Students' Views on Causes of Glossophobia Expounded}

In response to open-ended questions in the questionnaires, the study participants offered varied and interesting responses. This section presents a qualitative analysis of their responses summarized under the following five thematic areas: Students' background; past criticism by teachers; excessive use of vernacular; low selfesteem/confidence and the possible phobias they engender in the student when it comes to public speaking.

Students' Background: Participants observed that individual students' backgrounds could contribute to the fear of speaking in public. One respondent remarked, "A student who has all along been living in a village setting suddenly finding him/herself in a town/city setting and having to speak before large crowd can find the experience daunting." Another observed that the kind of upbringing the individual student receives before coming to tertiary level can impact negatively on their self-confidence as it can induce timidity. This observation corroborates Cherry's (2012) observation that an authoritarian parenting style, for instance, expects a child to adhere to strict rules established by parents or risk being punished. Other closely related references that confirm that participant's observation are those of Djane's (2014) and Amos' (2013) that in many cultural settings in Africa, it is almost a taboo for a child to talk when elders are talking: Children must keep quiet and listen. Such cultural practices breed timidity in many Ghanaian youth resulting in serious communication apprehension challenges later in life when they are expected to speak in public.

Past Criticism by the Teacher: Participants also cited past negative criticism by tertiary and/or primary school teachers as a possible factor that could dampen the spirit of a student to speak in public, a confirmation of Koshy's (2020) assertion that prior negative experiences in a foreign language context can contribute to learners' fear to speak in that language.

Excessive Use of Vernacular: Too much use of vernacular by students was also identified by study participants as having an adverse effect on students' ability to speak English in public. This finding affirms Kankam and Boateng's (2017) argument that overuse of vernacular is a major cause of apprehension engendered by the fear of making errors.

Low Self-Confidence: Participants in this study identified many factors that could conspire to result in glossophobia in students. A participant's observation that the "feeling that they are not educated enough to stand 
before others to talk on a formal occasion" provides a good summary. Non-conducive conditions in a student's former school could later affect them negatively at tertiary level when they are expected to speak English in public. As a result of the poor background conditions of students' former schools termed in Ghana as "deprived schools", they may be denied the prior experience of participating in public speaking through membership of such clubs as the Debating or Drama Club through which many accomplished public speakers cut their teeth. Consequently, many students come to tertiary level with an inferiority complex and poor communication skills because they neither had the exposure nor received enough training opportunities to practise public speaking. They are unable to speak English fluently as their grammar, vocabulary and pronunciation are also generally poor. As one participant pointed out, "We do not have the basic skills of organising materials for speech." This study also confirmed that some students are naturally shy and find it extremely difficult "to mingle or socialize", let alone stand before a crowd to speak. This poor prior preparation naturally predisposes the student to the phobia of speaking English in public.

The Phobias: Among the phobias identified by participants in this study are:

- fear of their teachers/guests on high table;

- fear of being added to the high table;

- fear of being asked questions;

- fear of offending the audience not only with what they may say amiss, but with some natural odours like "mouth odour" they may struggling with;

- fear of using the wrong choice of words/ lacking relevant vocabulary;

- fear of pronouncing words wrongly and being given nicknames by peers;

- fear from the uncertainty of the student not knowing the type of audience to expect;

- fear of crowd;

- fear of not meeting the dress code;

\subsection{Summary}

From the data collected it is clear that during public speaking there is always fear, nervousness and stage fright problems that come up. It is also clear that the phobia for public speaking is usually caused by fear of making a mistake, audience's reaction and speaking problems by the individual making the speech. The analysis also shows that majority of the students (30 out of 46) in Level 300 Business Secretarial class had delivered speech in public before at seminars, wedding and birthday parties; nonetheless, all the respondents $46(100 \%)$ admitted that public speaking created fear in them. The respondents also indicated that the fear of public speaking is caused by fear of being laughed at, natural shyness and spill of touch. There are various purposes for a student to speak in front of the public: It can be just to tell a story, to contribute to a discussion, to share an experience, to inform about a message, or to motivate others to take an action. Public speaking skills can be used for leadership/personal development, business, customer service, large group communication, and mass communication too. For instance, a good speaker can use their skill to get into personal sharing and show sincerity in what they are delivering and thereby stir up the audience's emotions. With confidence, a public speaker can use such skills to create an exciting atmosphere among the audience and thus increase their overall speech effectiveness.

\section{Conclusion}

This study investigated the causes of glossophobia in tertiary students. It involved 46 participants from the 2017 cohort of Secretaryship and Management students of the Wa Technical University in a case study. It was obvious from the respondents that the learning of public speaking skills was beneficial to students as they would be able to improve upon their personal and social interaction skills, academic communication, and most importantly, reap its immense benefits in their careers. Through the practice of effective public speaking, students would be able to build up confidence in persuading others more effectively on the ideas and opinion that they would like to share.

From the responses to the questionnaires administered, it was evident that despite participants' acknowledgement of the importance of public speaking, the fear (glossophobia) of practising it was real in tertiary students. Factors identified by respondents as accounting for public communication apprehension among students included the following: the fear to speak in front of a crowd; lack of confidence in speaking in public; inadequate public speaking exposure by students; timidity of students; fear of being laughed at; inexperience in public speaking; inadequate preparation on public speaking; fear of making grammatical errors in English by students; tension when speaking in public; fear of making mistakes and poor or inadequate vocabulary. The list is obviously not exhaustive, 
but given the scope of this paper, it suffices for our discussion. To help students overcome those challenges identified by our respondents, this study recommends, in the next subsection, a range of strategies and activities aimed at boosting students' confidence in speaking the English language in public.

\subsection{Proposed Strategies for Overcoming Glossophobia}

There are many avenues that tertiary institutions could explore to improve upon their students' performance in public speaking. One of the most important factors needing change in tertiary institutions in Ghana is an overhaul in the mode of language teaching, especially the teaching of public speaking. The task of equipping students with good public speaking skills should no longer be the preserve of the English teacher. It calls for an all-hands-ondeck approach. With the full support of the Academic Board, curriculums could be revised to include a set of oral communication requirements for all categories of students and disciplines. In addition, the design of all existing courses should be modified to incorporate more oral communication assignments. Regular and effective oral presentations individually in class by students should be encouraged. This would help students develop the skills of public speaking. This can be achieved if the age-old practice of lecturers giving volumes of notes to students during lecture sessions is discouraged and teaching made rather more practical in the form of presentations.

On the part of students, the single most important thing that they could do to make them successful in speaking publicly is proper prior preparation. Students should research on selected speech topics to get their facts and figures right before they venture mounting the podium to make a delivery. This will boost their confidence and help them overcome glossophobia. They should also put into practice the fundamentals of speech learnt:

i. Analysing a given speech occasion by asking: "Is the occasion formal, informal or a solemn one?"

ii. Choosing their diction and register carefully by asking: "Which words (diction) and expressions (register) are appropriate for the occasion?"

iii. $\quad$ Determining the audience by enquiring: "Who are expected? Are they males, females or a mixed-sex audience? What age bracket do they belong to? Are they youth only, adult only or mixed? What are their educational and/or professional backgrounds? What are their linguistic and socio-cultural backgrounds? What are their expectations?"

iv. How do I groom myself appropriately for the occasion?

v. What mannerisms should I observe or avoid on stage?

vi. How do I modulate my voice and pronounce words appropriately to capture the attention of my audience and have them understand my message?

vii. How do I avoid stage fright; while maintaining a stable voice and good eye-contact with my audience?

These questions are very crucial in determining what to put into a speech to make it suitable for a given occasion or audience. They constitute the basic principles of effective speaking as they serve as the generally accepted procedures for content preparation (BJU 1991).

With the help of smartphones and other recording devices, students can record (audio and/or video) their own speeches for replay to observe the modulation of their voices and how they were able to adopt appropriate enunciation and pronunciation strategies as well as how they observed acceptable stage mannerisms and maintained good eye-contact with the audience. The speech itself should be rehearsed before delivery in public. Sufficient time should be spent in practising. As much as possible, memorizing should be avoided, as forgetting of a single phrase or sentence can lead to very embarrassing consequences. It can easily throw one out of gear and increase one's anxiety before an audience and derail the flow of delivery.

To help students overcome glossophobic tendencies and improve upon their public speaking skills, the role of students should complement that of their teachers. On the part of students it is recommended that they make conscious efforts at seizing every possible opportunity to speak; whether it is on a formal or informal occasion. Initially, there may be some slips along the way, but with determination and constant practice, there can be improvement in their public speaking skills. Some of the surest ways of achieving this is to encourage them get into student politics by taking up leadership roles, or better still, joining relevant clubs and associations such as the Debating Club; Youth Parliament and Drama Troupe. Reading or listening to recorded speeches of great local and internationally acclaimed public speakers or watching their videos can also be of tremendous help to improving upon students' public speaking skills.

Lecturers, especially those who teach English Language and Communication Skills, should endeavor to create a friendly and supportive and non-threatening learning atmosphere to encourage students to speak English in and outside the classroom. They should intensify their research in communication apprehension to come out with 
training strategies that would significantly reduce students' anxiety to speak before the public. Students should be helped to eschew the thought that they are speaking because they are forced to do so and rather consider it as an opportunity to make their mark. Lecturers must also adopt student-centered techniques to teach so that the students can do all the talking, with lecturers only intervening when they think students need explanation. Lecturers must encourage students to boost their confidence in speaking publicly by organizing more seminars and workshops on public speaking skills to serve as practice; apportion sufficient time to rehearsing and promoting positive attitudes towards public speaking in order to improve students' oral communicative skills in English. A general interactive approach to teaching and teacher roles using communication strategies, promoting positive attitudes and a positive atmosphere are also useful strategies that could help boost students' public speaking skills. There should be improvement in English proficiency, expansion of vocabulary and better preparation and practice of oral English. Students should also be trained in the use of modern information and communication technologies like the PowerPoint and other audio-visual aids to enhance their public speaking skills.

\subsection{Directions for Future Research}

The current study was limited to one tertiary institution - the Hilla Limann Technical University, Wa. Given that there are over a hundred tertiary institutions in the country, the results of the study cannot be generalized. It would be interesting to conduct a future research that would compare the causes in of glossophobia in other universities to identify the similarities and differences that may exist on various campuses. It would also be interesting to compare the levels of speech anxiety between female students and their male colleagues.

\section{References}

Amos, P. M. (2013). Parenting culture - Evidence from some African communities. https://doi.org/10.5772/56967

Bailey, K. M. (2012). Practical English language teaching speaking. New York, Mc Graw-Hill.

Barnard, D. (2017). The importance of eye contact during a presentation. Retrieved 23/01/21 from http://www.virtualspeech.com

Beebe, S., \& Beebe, S. (2021). Public speaking: An audience-centred approach. $11^{\text {th }}$ Edn. Pearson. ISBN-13: 9780135729151. Retrieved 14/01/21 from http://www.pearson.com

Black, R. (2019). Glossophobia (Fear of public speaking): Are you glossophobic? Retrieved 23/01/21 from http://www.psycom.net

Bob Jones University (BJU). (1991). Fundamentals of Speech. Greenville: BJU Press.

Bress, P. (2006). Meeting Objectives, English Teaching Professional. July, (45), 14-15.

Brown, H. D. (2002). Strategies for success: A practical guide to learning English. New York, Longman.

Cherrry, K. (2012). The four styles of parenting. Retrieved 03/01/21 from http://www.psychology.about.com/od/developmentalpsychology/a/parenting-style.htm

Christensen, J. P. (2002). Understanding and conducting a successful presentation assignment. Guidelines, 24(2), 23-28.

Chu, C. W. L. (2001). Reflective assessment materials for ELT teachers. The English Teacher, 4(3), 243-251.

Croston, G. (2012). Psychology Today. The thing we fear more than death: Why predators are responsible for our fear of public speaking. Retrieved 01/01/21 from https://www.psychologytoday.com/us/blog/the-real-storyrisk/201211/the-thing-we-fear- more-death

Crystal, D. (2003). English as a Global Language. 2nd Ed. Cambridge: Cambridge University Press. https://doi.org/10.1017/CBO9780511486999

Dansieh, S. A. (2015). Quality Issues in Teaching and Learning English at Tertiary Level in Ghana. A thesis submitted for the degree of Doctor of Business Administration. Bath: University of Bath.

Djane, A. (2014). What happened to our youth? New African Magazine. Retrieved 01/01/21 from https://newafricanmagazine.com/6148/

Du Plooy-Cillier, F., \& Louw, F. M. (2014). Let's talk about interpersonal communication. $1^{\text {st }}$ Ed. Cape Town: Pearson Education.

Encyclopedia.com (2021). Speaking. The Oxford Pocket Dictionary of Current English. Retrieved 26/02/21 from https://www.encyclopedia.com/humanities/dictionaries-thesauruses-pictures-and-press-releases/speaking

Fish, B. (2001). In “Do you suffer from glossophobia?” Retrieved 01/01/21 from http://www.glossophobia.com/ 
Fulton, Robert Irving. (2011). College Courses in Public Speaking. The English Journal, 3.3(1914), 160-165. JSTOR. Web. 22 September 2011. https://doi.org/10.2307/801489

Gallo, C. (2006). The 10 worst presentation habits. BusinessWeek.com. Retrieved December 7, 2017 from http://images.businessweek.com/ss/06/02/mistakes/index_01.htm

Genard, G. (2019). Speak for Success: 10 causes of speech anxiety that create fear of public speaking. Retrieved 11/01/21 from http://www.genardmethod.com

Hadfield, J., \& Charles (2008). Introduction to teaching English. Oxford University Press. Eigal S. A. Portugal.

Harmer, J. (2007). How to teach English. Pearson Education Limited. Essex, England. https://doi.org/10.1093/elt/ccn029

Harmer, J. (2007). The Practice of English Language Teaching. Pearson Education. Limited. Essex, England.

Hashemi, M. (2011). Language stress and anxiety among the English language learners. Procedia - Social and Behavioral Sciences, 30(2011), 1811-1816. https://doi.org/10.1016/j.sbspro.2011.10.349

Hindo, Cindy S., \& González-Prendes, A. Antonio. (2011). One-Session Exposure Treatment for Social Anxiety with Specific Fear of Public Speaking. Research on Social Work Practice, 21.5(2011), 528-538. SAGE Publication.Web. 22 September 2011. https://doi.org/10.1177/1049731510393984

Hornby, A. S. (2005). Oxford Advanced Learner's Dictionary. Oxford University Press. China.

Hyland, K. (2006). English for Academic Purposes: An Advanced Resource Book. London: Routleddge. https://doi.org/10.4324/9780203006603

Johnston, J. E. (2006). The complete idiot's guide to controlling anxiety. Indianapolis: Alpha Books.

Kankam, P. K., \& Boateng, S. O. (2017). Addressing the problem of speech anxiety among students. International Journal of Public Leadership, 13(1), 26-39. https://doi.org/10.1108/IJPL-07-2016-0029

Koshy, B. (2020). Xenoglossophobia among second language learners. International Journal of Creative Research Thought, 8(2). ISSN: 2320-2882. Retrieved 20/04/21 from http://www.ijcrt.org

Krannich, C. R. (2004). 101 Secrets of highly effective speakers: Controlling fear, commanding attention [Recorded by B. McDonald]. [CD]. New York: Listen \& Live Audio, Inc.

Kushner, M. (2004). Public Speaking For Dummies. (2nd ed.), New Jersey, USA, John Wiley \& Sons.

Liu, Meihua.(2011). Anxiety in Oral English Classrooms: A Case Study in China. Indonesian Journal of English Language Teaching, 3.1(2007a), 119-137. Google Scholar. Wed. 11 November 2011. https://doi.org/10.1057/9780230299481_6

Louise Katz Ph.d (2000). public speaking anxiety, University of Tennessee at martin counseling and career services.

Lumen Learning. (2017). Speech anxiety: Fundamentals of Public Speaking. Retrieved 27/01/21 from http://www.courses.lumenlearning.com

MacIntyre, P. D., \& Gardner, R. C. (1994). The subtle effects of language anxiety on cognitive processing in the second language. Language Learning, 44(2), 283-305. https://doi.org/10.1111/j.1467-1770.1994.tb01103.x

McCroskey, J. C. (2001). An introduction to rhetorical communication. Boston, MA: Alyn and Bacon.

O’Neil, D. (2006). What Is Culture. Human Culture: An Introduction to the Characteristics of Culture and the Methods used by Anthropologists to Study It. Retrieved 01/01/21 from http://anthro.palomar.edu/culture/culture_1.htm

Parvis, L. F. (2001). The importance of communication and public-speaking skills. Journal of Environmental Health, 63, pp. 44, 35.

Present Glossophobia.com (2001). Do you suffer from glossophobia? Retrieved 01/01/21 from http://www.glossophobia.com/

Scovel, T. (1991). The effect and affect on foreign language learning: A review of anxiety research. in E. K. Horwitz and D. J. Young, Language Anxiety, 101-108. Englewood Cliffs, NJ: Prentice Hall.

Segar, G. (2018). Types of public speaking anxiety. Retrieved 22/01/21 from http://www.potentspeaking.com

University of Minnesota Libraries. (2011). Stand up, speak out. University of Minnesota Libraries Publishing. Retrieved from http://www.ssrebus.community 


\section{Copyrights}

Copyright for this article is retained by the author(s), with first publication rights granted to the journal.

This is an open-access article distributed under the terms and conditions of the Creative Commons Attribution license (http://creativecommons.org/licenses/by/4.0/). 